\title{
DESENVOLVIMENTO DE UM SISTEMA DE GERENCIAMENTO DA ARBORIZAÇÃO URBANA PARA O MUNICÍPIO DE CAXIAS DO SUL, RS
}

\author{
DEVELOPMENT OF A URBAN AFFORESTATION MANAGEMENT SYSTEM FOR \\ CAXIAS DO SUL, RS
}

Morgana Rech ${ }^{1}$, Eduardo Marques Martins ${ }^{2}$

\begin{abstract}
RESUMO
O presente trabalho apresenta o desenvolvimento de um banco de dados geográficos (BDG) para o gerenciamento da arborização urbana em âmbito municipal. O BDG foi criado em ambiente de Sistemas de Informações Geográficas, e contém uma classe de feições das árvores existentes em praças, parques e vias públicas da área urbana. Foram criadas tabelas alfanuméricas não espaciais para informações sobre: espécies e suas características; avaliações dos exemplares arbóreos; solicitações, deferimentos e indeferimentos, e execução de corte e poda. Essas tabelas foram relacionadas à classe "árvores", o que permitiu consultas e geração de relatórios para diferentes atributos. Foi elaborado um Dicionário de Dados, a fim de descrever a estrutura e facilitar o uso do BDG. A implantação do Sistema de Gerenciamento da Arborização Urbana de Caxias do Sul (SisGAU) poderá: (a) auxiliar no monitoramento e conhecimento da arborização urbana; (b) contribuir para a melhoria dos serviços públicos relacionados à arborização; e (c) fornecer subsídios para ações planejadas na implantação e manutenção da arborização urbana. Além disso, o BDG criado permite disponibilizar na web informações sobre a arborização, o que contribui para o aumento da consciência ambiental da população.
\end{abstract}

Palavras-chave: Banco de dados geográficos; Sistema de informações geográficas; Poda; Árvores; Secretaria do Meio Ambiente.

\section{ABSTRACT}

This paper presents the development of a geodatabase (GDB) for the municipal management of urban trees. The GDB was created in a Geographic Information System software, and contains a feature class of existing trees in squares, public parks and roads in the urban area. Alphanumeric tables were created, with information about: species and their characteristics, arboreal specimens' assessments, requests, concessions and denials, and cutting and pruning executions. These tables were related to "árvores" class, allowing consultation and quick reports for different attributes. A Data Dictionary was developed in order to describe the structure of the GDB and facilitate their use. The implementation of the Management System of Urban Forest in Caxias do Sul (SisGAU) will: (a) assist in knowledge and monitoring of urban forest; (b) contribute to the improvement of public services for the management of the urban trees; and (c) provide subsidies to promote planned action in the implementation and maintenance of urban trees. In addition, the GDB will provide information on the web about the urban forest, contributing to increase the environmental awareness of the population.

Keywords: Geodatabase; Geographic information system; Pruning; Trees; Environment Department.

Recebido em 16.09.2016 e aceito em 03.11.2016

1 Bióloga, MSc., aluna do Curso de Especialização em Geoprocessamento da Faculdade da Serra Gaúcha (FSG), Caxias do Sul/RS. E-mail: morgana_rech@yahoo.com.br

2 Geógrafo, MSc., doutorando em Geociências pela Universidade Federal do Rio Grande do Sul (UFRGS), Professor do Curso de Especialização em Geoprocessamento da Faculdade da Serra Gaúcha (FSG) e Professor Substituto da Universidade Federal de Santa Catarina (UFSC), Florianópolis/SC. E-mail: geo.edum2@gmail.com 


\section{INTRODUÇÃO}

No presente trabalho, o termo arborização urbana refere-se ao conjunto das árvores existentes em passeios públicos e canteiros centrais, ou arborização viária (MAYER; OLIVEIRA FILHO; BOBROWSKI, 2015; OLIVEIRA et al., 2015), e às árvores existentes em parques e praças (SCHALLENBERGER et al., 2010).

As árvores exercem benefícios importantes ao ambiente urbano, a saber: melhoria do microclima, através da diminuição da temperatura e da amplitude térmica, e do sombreamento; melhoria da qualidade do ar; redução da poluição sonora e visual; fornece abrigo e alimento para a avifauna; promove a estabilidade emocional e a redução do estresse (benefícios psicológicos), visto que são capazes de transmitir sentimentos de harmonia, paz e tranquilidade; propicia harmonia estética; e promove a educação ambiental (benefício social), ao permitir, pelo contato e como instrumento pedagógico, que a população aprenda a reconhecer e perceber o meio ambiente e os processos naturais (OLIVEIRA FILHO; SILVA, 2010; SPADOTTO; DELMANTO JR., 2009; OLDFIELD et al., 2013; MAYER; OLIVEIRA FILHO; BOBROWSKI, 2015; MEIRA et al., 2015).

No entanto, sem o devido planejamento, as árvores podem apresentar conflitos diretos e indiretos com outros componentes urbanos, e trazer prejuízos e transtornos, tais como: interrupção no fornecimento de energia elétrica, entupimento de redes de esgoto e/ou pluvial, danos a edificações, obstáculos para circulação e acidentes envolvendo pedestres e veículos (SPADOTTO; DELMANTO JR., 2009; MEIRA et al., 2015). Para evitar ou remediar o conflito de espécies inadequadas, é necessário o manejo dos indivíduos arbóreos, através da realização de podas, ou mesmo sua remoção, sendo essas atividades as mais onerosas relacionadas à manutenção da arborização de ruas (OLIVEIRA et al., 2015). Assim, o planejamento e o monitoramento da arborização urbana são fundamentais para permitir a convivência harmônica entre a população e as árvores nos centros urbanos (SPADOTTO; DELMANTO JR., 2009; NUNES et al., 2013; OLIVEIRA et al., 2015).

Para o monitoramento das árvores de rua é necessário, primeiramente, o conhecimento do patrimônio arbóreo existente na cidade (ROSSETTI; PELLEGRINO; TAVARES, 2010; SCHALLENBERGER et al., 2010). Diversos estudos tem sido realizados no intuito de caracterizar a arborização de praças, parques, campus universitários, bem como a arborização viária de bairros ou centros urbanos (FARIA; MONTEIRO; FISCH, 2007; ALMEIDA; RONDON NETO, 2010; RABER; REBELATO, 2010; ALBERTIN et al., 2011; FALCE et al., 2012; NUNES et al., 2013; MARANHO; PAULA, 2014; MEIRA et al., 2015; LIMA NETO et al., 2016; PERIOTTO et al., 2016). No entanto, em um ambiente dinâmico como o meio urbano, um inventário voltado para a manutenção e manejo da arborização urbana deve ser contínuo, para 
manter dados e informações sempre atualizados (FRANCO, 2006). Esse tipo de inventário permite verificar mudanças ocorridas na composição e crescimento das árvores e, dessa forma, possibilita a implantação de um programa de gerenciamento das árvores, bem como a definição de uma política de administração de longo prazo (LIMA NETO, 2011).

A informatização dos dados de um inventário possibilita o armazenamento, a análise e a atualização de um grande volume de dados e informações geradas por um inventário. Ademais, o mapeamento georreferenciado das árvores através de um Sistema de Informações Geográfica (SIG) permite a fusão das informações relativas às árvores (variáveis que descrevem as características de cada indivíduo) com um Banco de Dados Geográfico (BDG) (FRANCO, 2006; LIMA NETO, 2011). Assim, diversos estudos recentes de arborização urbana têm incluído a informatização e o georreferenciamento dos dados obtidos nos inventários, bem como o uso de diferentes geotecnologias (FALCE et al., 2012; MARANHO; PAULA, 2014; MAYER; OLIVEIRA FILHO; BOBROWSKI, 2015; LIMA NETO et al., 2016). Dentre diferentes geotecnologias, o SIG tem sido sugerido por diferentes autores para auxiliar a gestão da arborização urbana (MAYER; OLIVEIRA FILHO; BOBROWSKI, 2015; OLIVEIRA et al., 2015), uma vez que a implantação de um sistema para cadastro e controle das espécies vegetais possibilita o gerenciamento de tarefas de manejo da arborização de forma sistemática e automatizada (FRANCO, 2006).

Um sistema de geoprocessamento é destinado ao processamento de dados georreferenciados (SPADOTTO; DELMANTO JR., 2009; LIMA NETO, 2011), os quais têm como característica principal a indicação de uma posição específica do globo terrestre, por meio de suas coordenadas (CÂMARA et al., 1996). Um SIG pode ser definido como o conjunto de técnicas relacionadas com a coleta, o armazenamento, a manipulação, a edição, a análise e a apresentação de dados espaciais georreferenciados (CÂMARA et al., 1996; SPADOTTO; DELMANTO JR., 2009), com o intuito de melhor compreender fenômenos e subsidiar decisões. Os dados geográficos manipulados pelos SIG requerem sua representação e gerenciamento em BDGs, os quais têm seus dados usualmente agrupados em dois componentes: o convencional (alfanumérico) e o espacial (relacionado à natureza geográfica), que pode ser dos tipos geo-objeto ou geo-campo (CÂMARA et al., 1996).

Para a gestão da arborização urbana em ambiente SIG, é imprescindível que o BDG seja orientado principalmente às árvores (geo-objetos), pois elas são consideradas como principais elementos de intervenção. Entre as propostas de modelagem aplicadas aos BDGs, o modelo relacional é o mais utilizado atualmente (MECENAS; OLIVEIRA, 2005). Nesse modelo, a identidade é uma característica imutável, que possibilita a distinção entre os geo-objetos, e o relacionamento entre tabelas ocorre por meio de chaves denominadas "estrangeiras" (MECENAS; OLIVEIRA, 2005). Essas chaves permitem cruzamentos entre dados e a 
manutenção da integridade das informações e do histórico de registros e ações. Com o cruzamento de informações, os atributos relacionados ficam disponíveis para ajudar a analisar os dados e resolver problemas espaciais; além disso, a atualização dos dados torna-se mais simples, e elimina-se a necessidade de atualizar dados redundantes (CASANOVA et al., 2005).

Uma ferramenta importante e de uso crescente para a elaboração e na disseminação do uso de BDGs é o Dicionário de Dados. Segundo Casanova et al. (2005), consiste na elaboração de um vocabulário que contenha o identificador, a localização e a descrição das feições e das características dos atributos dos geo-objetos de interesse. Ainda segundo o autor, o objetivo do seu uso é ter um mecanismo para identificar a existência de dados, a sua qualidade, como acessá-los e utilizá-los, além de permitir a integração e interoperabilidade dos dados.

O Decreto Municipal № 16.882/2014 (CAXIAS DO SUL, 2014) dispõe sobre as "Normas de Arborização Urbana" no âmbito do município de Caxias do Sul, Rio Grande do Sul. No que tange os serviços de implantação e manutenção da arborização urbana, o Decreto № 16.882/2014 define que cabe à Secretaria Municipal do Meio Ambiente (SEMMA) o plantio e a manutenção das mudas plantadas na arborização urbana. Em relação à manutenção da arborização em área pública, o Art. 15ำ do mesmo decreto dispõe que as podas, quando necessárias, serão executadas pela SEMMA, exceto sob rede de energia elétrica, onde a

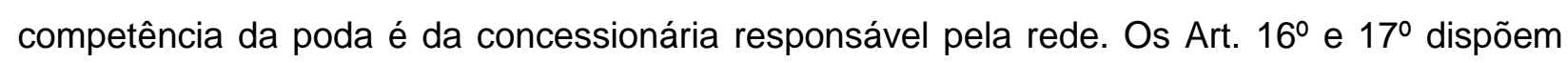
que fica a cargo da SEMMA a análise e autorização para a realização de transplante ou supressão de exemplares arbóreos localizados em áreas públicas. Salienta-se que a execução de transplantes e cortes compete à SEMMA, no entanto, em situações pré-estabelecidas, pode ficar a cargo do empreendedor ou do proprietário do imóvel lindeiro à área pública em questão. O Setor de Praças, Parques e Jardins (PPJ) é o Setor da SEMMA responsável pelo manejo e pela análise das solicitações de intervenção de exemplares arbóreos localizados em área pública (poda, transplante ou supressão).

Nesse contexto, o objetivo deste trabalho é o desenvolvimento do Sistema de Gerenciamento da Arborização Urbana (SisGAU), baseado na construção de um BDG em ambiente de SIG. O SisGAU foi projetado para servir como ferramenta para aplicação no planejamento, gerenciamento e execução dos serviços prestados e nas atividades relacionadas à arborização urbana desenvolvidas pela SEMMA de Caxias do Sul. 


\section{MATERIAL E MÉTODOS}

O trabalho foi desenvolvido no município de Caxias do Sul, Rio Grande do Sul, Brasil, localizado na Encosta Superior do Nordeste, a uma altitude entre 760 e $800 \mathrm{~m}$, entre as coordenadas $28^{\circ} 22^{\prime}$ e $29^{\circ} 19^{\prime}$ de latitude Sul, e $51^{\circ} 91^{\prime}$ e $50^{\circ} 46^{\prime}$ de longitude Oeste. Ocupa uma área de 1.644 km² de extensão, inserido no Bioma Mata Atlântica, com vegetação dos tipos Floresta Ombrófila Mista e Floresta Estacional Decidual, o clima é mesotérmico brando superúmido, e a população estimada, em 2014, era de 470.223 habitantes (IBGE).

O desenvolvimento da proposta metodológica para construção do SisGAU compreendeu as seguintes etapas:

(i) Modelagem do BDG;

(ii) Criação do BDG em ambiente de SIG;

(iii) Alimentação do BDG com dados disponibilizados pela SEMMA;

(iv) Teste e avaliação das funcionalidades do SisGAU.

Para a visualização e marcação dos indivíduos arbóreos em ambiente de SIG, foram utilizadas fotografias aéreas ortorretificadas obtidas pela Prefeitura nos anos de 2013 e 2014 (ortofotos), com resolução espacial de $0,10 \mathrm{~m}$. As bases cadastrais existentes no Banco de Dados da Prefeitura de Caxias do Sul, com dados georreferenciados do sistema viário, bairros, loteamentos, quadras, lotes e áreas verdes, entre outros, foram utilizadas para a obtenção do endereço das árvores (localização).

Os dados e informações sobre os indivíduos arbóreos são oriundos do projeto "Inventário da Arborização Urbana", contratado pela SEMMA. Os dados parciais disponibilizados pela SEMMA contém a identificação de parte dos indivíduos arbóreos localizados em passeios públicos e canteiros centrais na área urbana do município. $O$ levantamento contempla ainda parâmetros de condição fitossanitária e dendometria de cada indivíduo, além da descrição dos conflitos com equipamentos públicos. O BDG também foi projetado para armazenar informações de licenciamento ambiental e autorização para poda, supressão e transplante de exemplares arbóreos, assim como novas avaliações dos exemplares realizadas pelos técnicos da SEMMA e informações sobre serviços a serem executados pela SEMMA.

Foi elaborado um Dicionário de Dados para o BDG com a finalidade de descrever a sua estrutura e perpetuar a sua lógica de funcionamento. Consiste de uma tabela geral, com o nome e a descrição de cada classe (geográfica e não-geográfica), e de um conjunto de tabelas específicas, com informações referentes a cada classe, a saber: descrição genérica do objetivo e da forma de representação, e atributos (nome, formato, tamanho e descrição). Nos casos de atributos vinculados a domínios específicos (classes de informação pré-determinadas), os 
valores possíveis também foram mostrados na descrição do atributo. Além disso, para cada atributo, foi informado se o mesmo é um "atributo chave" (identificador) e se permite valores nulos (não obrigatoriedade de inserção de informações).

A modelagem do BDG foi realizada com o uso do programa BRModelo®. Foi utilizado um modelo relacional orientado a geo-objetos, com um esquema conceitual, representando as entidades existentes no BDG, seus atributos e os relacionamentos entre elas. Após a modelagem, a construção do BDG foi realizada utilizando-se o programa ArcGis® 10.3 (ESRI, 2015).

O BDG criado contém uma classe de feições "árvores" do tipo pontos para o cadastro dos indivíduos arbóreos existentes em praças, parques e vias públicas, na área urbana do Município. Os pontos correspondentes às árvores foram inseridos através da importação dos dados disponibilizados pela SEMMA.

Além dos dados geográficos, foram criadas tabelas alfanuméricas não espaciais para o armazenamento de informações sobre: espécies arbóreas e suas características; avaliações de exemplares arbóreos; solicitações de corte e de poda; deferimentos de corte e de poda; indeferimentos de corte e de poda; execução de corte e de poda. A fim de aumentar a segurança do banco de dados e evitar erros de digitação, foram criados domínios para campos cujas informações servem de filtro para futuras consultas. Os referidos domínios foram, então, vinculados aos campos correspondentes nas tabelas e feições criadas no BDG. Concluída a elaboração de todas as tabelas, foram criadas as classes de relacionamento com o Plano de Informações (PI) "árvores" e entre as diferentes tabelas, com o vínculo de atributos chave e definição das cardinalidades de cada relacionamento (formas de associação entre informações).

O BDG também foi projetado para cadastrar todas as solicitações de manejo de árvores em áreas públicas protocoladas na SEMMA. Assim que uma solicitação é analisada, é informado se a mesma foi deferida ou indeferida e a justificativa da decisão. Por fim, para os serviços de poda, supressão e transplante executados pela Secretaria, o BDG permite o armazenamento de informações sobre o tipo de manejo e a data da execução, cujos registros são vinculados ao indivíduo arbóreo e à solicitação correspondente.

Rotinas de consulta por atributos foram transformadas em ferramenta através do módulo ModelBuilder, disponível no software de SIG utilizado. Além disso, com o objetivo de otimizar a atuação de técnicos da SEMMA, foram criados relatórios automatizados para as referidas consultas, com os campos a serem mostrados e as seleções pré-estabelecidas.

Os dados de avaliação de estado fitossanitário dos exemplares arbóreos existentes na arborização urbana podem ser atualizados sempre que um técnico da SEMMA executar uma vistoria in loco, em decorrência da existência de solicitação de manejo (corte ou poda). Dessa 
forma foi criada a condição para a manutenção e atualização do histórico da evolução do estado fitossanitário de cada árvore. A fim de manter o inventário atualizado, cada vez que uma árvore for suprimida, a informação espacial dessa árvore poderá ser removida do SIG, enquanto que o seu histórico será mantido nas tabelas alfanuméricas. Da mesma forma, cada árvore que for plantada na arborização urbana pela Secretaria poderá ser incluída no SIG e no BDG.

Após a criação do BDG, de acordo com as especificações constantes no modelo conceitual e no Dicionário de Dados, foram importados os primeiros dados parciais obtidos no Inventário e disponibilizados pela SEMMA, e realizados os seguintes testes: geração de consultas por atributos, relacionamentos e localização espacial; geração de relatórios padronizados; edições e adição de dados (geográficos e não-geográficos); e visualização de dados e informações.

Ademais, foram inseridos alguns dados simulados referentes a solicitações, indeferimentos, deferimentos e execução de podas e cortes com o objetivo de verificar a operacionalidade da aplicação dessas funcionalidades no desenvolvimento das atividades e serviços cotidianos desempenhados pela SEMMA.

Com o intuito de avaliar a importância da adoção de estratégias de repasse de informações operacionais e interpretativas em âmbito corporativo para o sucesso na implementação de projetos que utilizam geotecnologias, o Dicionário de Dados foi apresentado a funcionários que não participaram ativamente da implantação do SisGAU para avaliar a sua pertinência.

\section{RESULTADOS E DISCUSSÃO}

A criação do modelo conceitual (Figura 1) serviu como base para o desenvolvimento do BDG, o que facilitou o estabelecimento dos relacionamentos necessários entre as diferentes classes (geográficas e não-geográficas) e da cardinalidade de cada relacionamento no ambiente de SIG. A visualização do BDG em um esquema geral auxilia no entendimento de sua estrutura e funcionamento, sem a necessidade de conhecimentos mais específicos de softwares de SIG. O Dicionário de Dados também descreve a estrutura e as regras do BDG, com o detalhamento dos campos de cada tabela ou classe de feição. O uso desse dicionário de dados tem o intuito de facilitar a continuidade do uso do SisGAU na SEMMA, através do melhor entendimento da estrutura, características e formas de uso e aplicações do referido banco para todos os funcionários. Nos testes realizados, o Dicionário de Dados permitiu aos funcionários que não participaram ativamente do desenvolvimento do SisGAU compreender 
mais facilmente o seu funcionamento, condição que potencializa, como esperado, a autonomia e minimiza a necessidade de reuniões de nivelamento técnico e a dependência de conhecimento pessoal de outros colegas de trabalho.

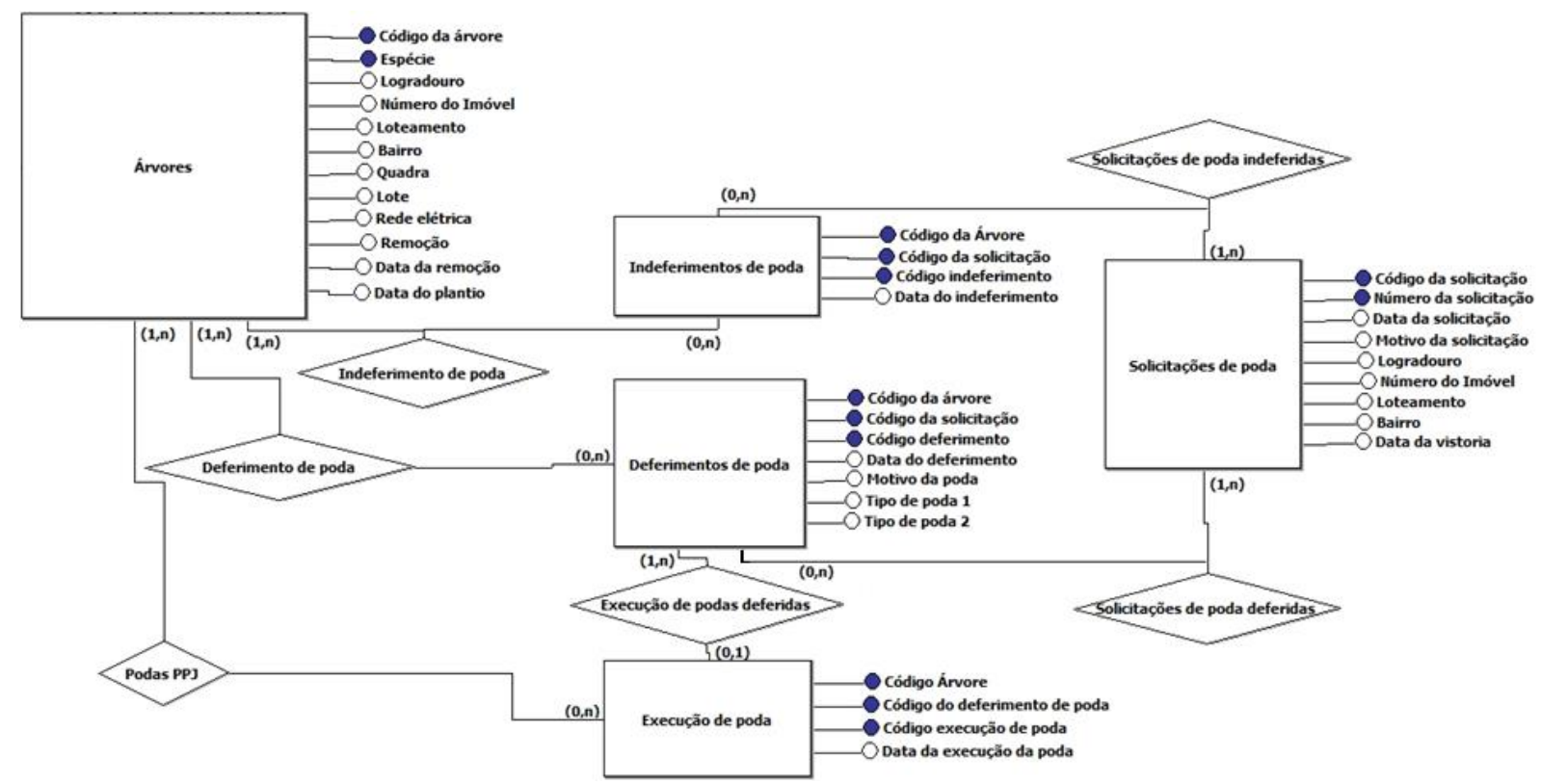

Figura 1. Parte do modelo conceitual elaborado. Os retângulos representam cada tabela (geográfica ou não-geográfica), com seus atributos (círculos azuis representam atributos chave). Os losangos representam os relacionamentos entre as diferentes tabelas, e os números entre parênteses indicam a cardinalidade de cada relacionamento

Figure 1. Part of the elaborated conceptual model. The rectangles represent each table (geographic or non-geographic), with its attributes (blue circles represent key attributes). The diamonds represent the relationships among the different tables, and the numbers in parentheses indicate the cardinality of each relationship

Com a inserção dos dados de 2046 indivíduos arbóreos no BDG, o SisGAU permitiu a consulta dos mesmos através de atributos como: espécie, estado fitossanitário e conflitos com equipamentos urbanos. Foram automatizadas rotinas de consulta por atributos para exemplares mortos e para exemplares em mau estado fitossanitário, bem como criados relatórios para as referidas consultas, com os campos a serem mostrados e as seleções préestabelecidas. As seleções e relatórios de exemplares mortos e em mau estado fitossanitário viabilizam a implementação de estratégias de remoção e substituição desses exemplares de maneira regionalizada, o que otimiza a atuação dos técnicos da SEMMA, além de minimizar riscos à vida e ao patrimônio.

Após a inserção dos dados simulados, ao selecionar um indivíduo arbóreo, foi possível obter um histórico da evolução do seu estado fitossanitário, o que é facilitado pela geração de um relatório com campos pré-definidos, conforme pode ser visualizado na Figura 2. Da mesma forma, foi possível obter um histórico referente a podas deferidas ou indeferidas e do tipo de poda executada para cada exemplar. Até o momento, não se tem conhecimento de nenhum 
inventário contínuo com dados de históricos de exemplares arbóreos disponibilizados em ambiente de SIG. No entanto, entende-se que esta ferramenta é de grande valia para o poder público, pois permite a análise da evolução de indivíduos de diferentes espécies e, assim, pode auxiliar na tomada de decisão para plantios futuros.

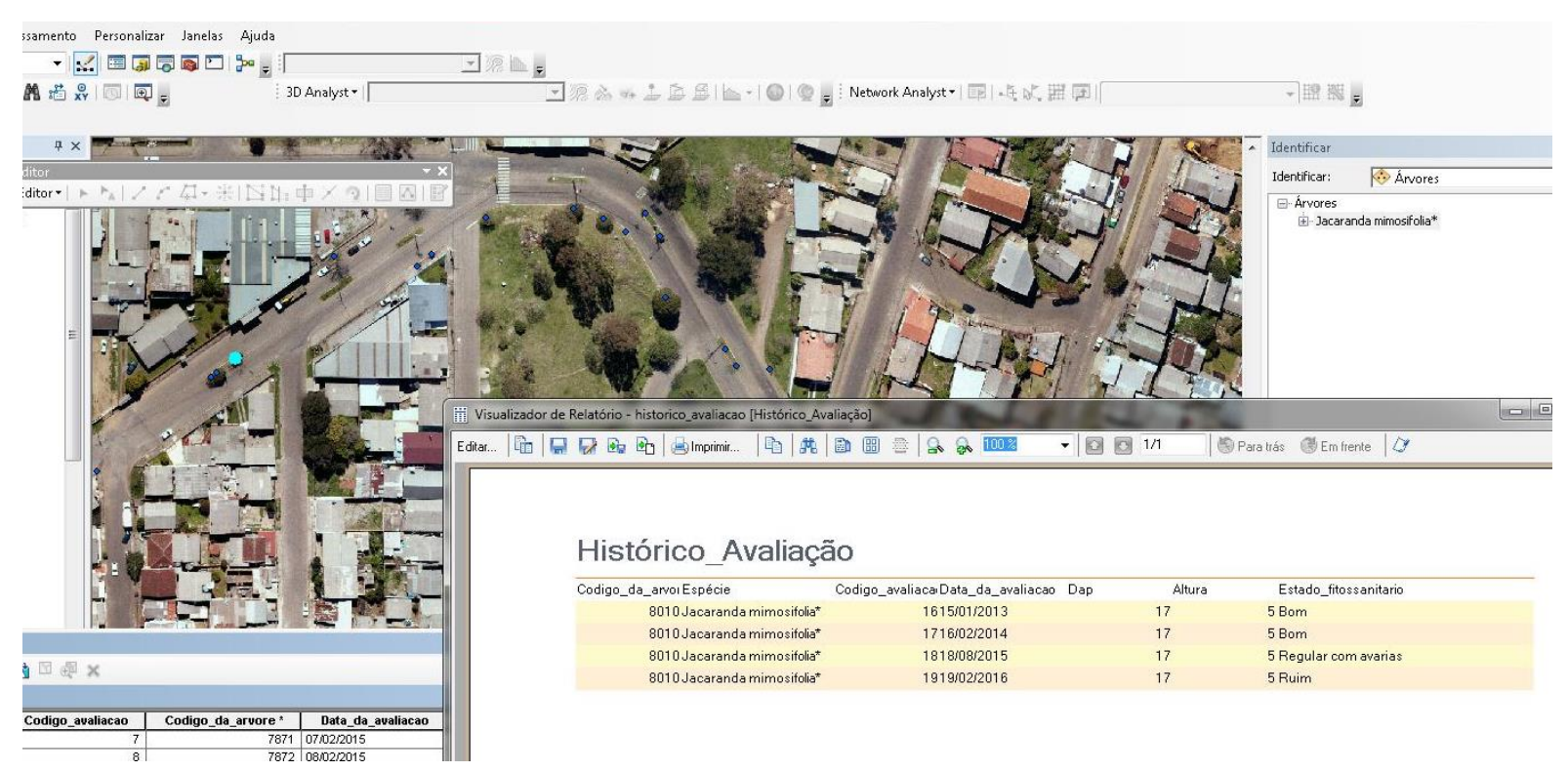

Figura 2. Consulta do histórico da avaliação de exemplares arbóreos, através da execução de relatório, a partir de um indivíduo selecionado na classe de feição árvores

Figure 2. Historical evaluation of arboreal specimens through report implementation from an individual selected in the feature class "árvores" (trees)

A consulta por indivíduo também possibilitou visualizar o histórico de pedidos de corte indeferidos e a existência de Alvará de supressão, bem como a informação da execução de corte e motivo da supressão. A Figura 3 mostra a estrutura do BDG criado e apresenta um exemplo da visualização das informações dos indivíduos arbóreos na plataforma ArcMap®.

Foram incluídos dados simulados referentes a avaliações técnicas, cortes e podas. Com essa simulação, foi possível verificar que o SisGAU possibilita a organização do serviço de manutenção da arborização urbana. A partir de consultas por atributos das tabelas relacionadas com o PI "árvores" no BDG, o mesmo possibilita a visualização espacial dos exemplares arbóreos a serem podados ou suprimidos. A fim de facilitar o uso do SisGAU por um maior número de técnicos, sem necessidade de conhecimentos avançados do software de SIG utilizado, foram criadas fórmulas para as seleções por atributos para "cortes a executar" e para "podas a executar". A Figura 4 mostra a seleção por atributos criada para selecionar os exemplares arbóreos com podas deferidas e ainda não executadas. As seleções foram também incluídas na ferramenta ModelBuilder, o que facilita a obtenção automática dos dados, de maneira rápida e precisa. 

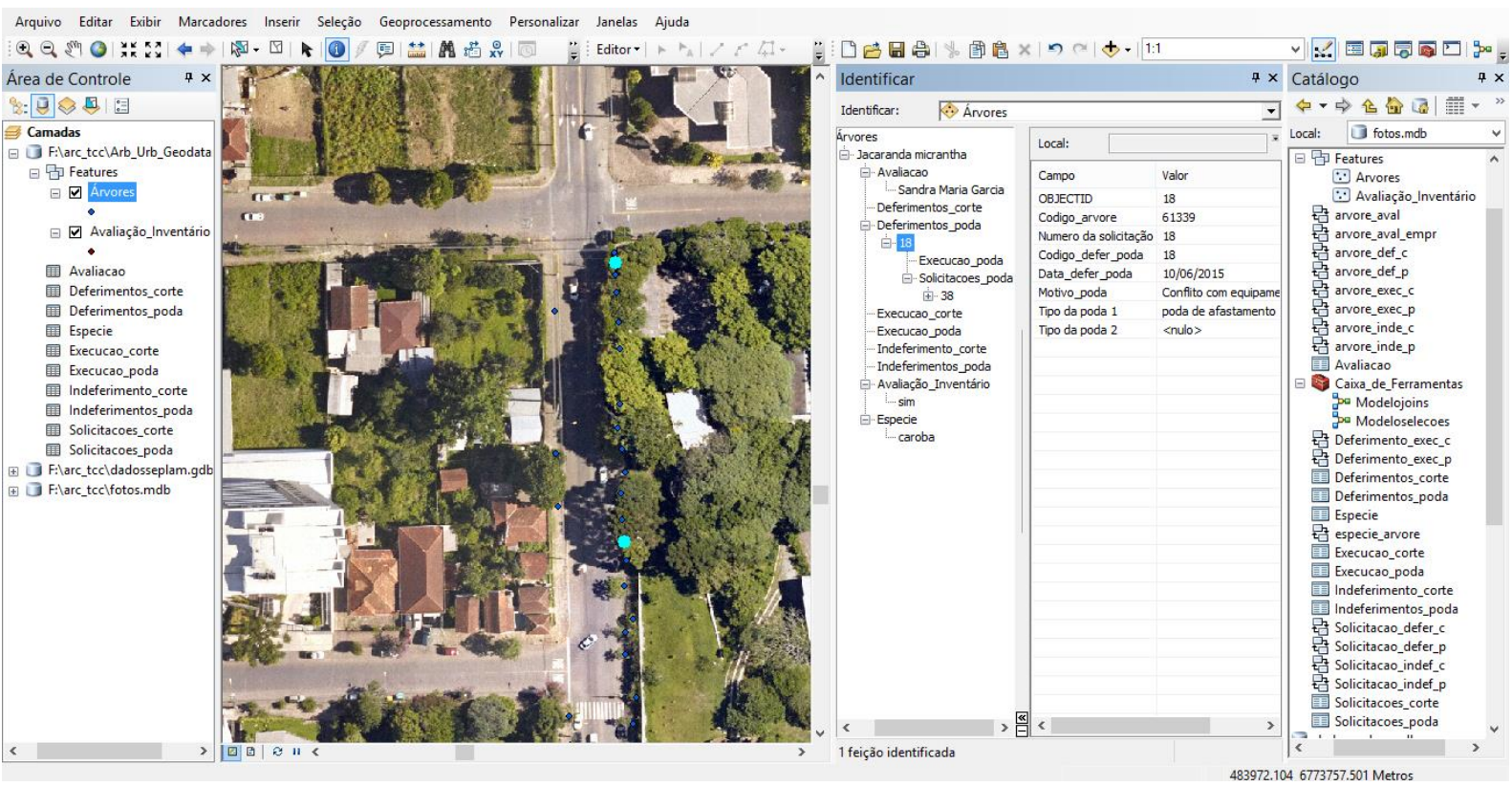

Figura 3. Estrutura do BDG criado no $\operatorname{ArcMap} \AA$ e forma visualização das informações de um indivíduo arbóreo constante na classe de feição árvores

Figure 3. BDG structure created in ArcMapß and display form of information from an arboreal individual in the feature class "árvores" (trees)

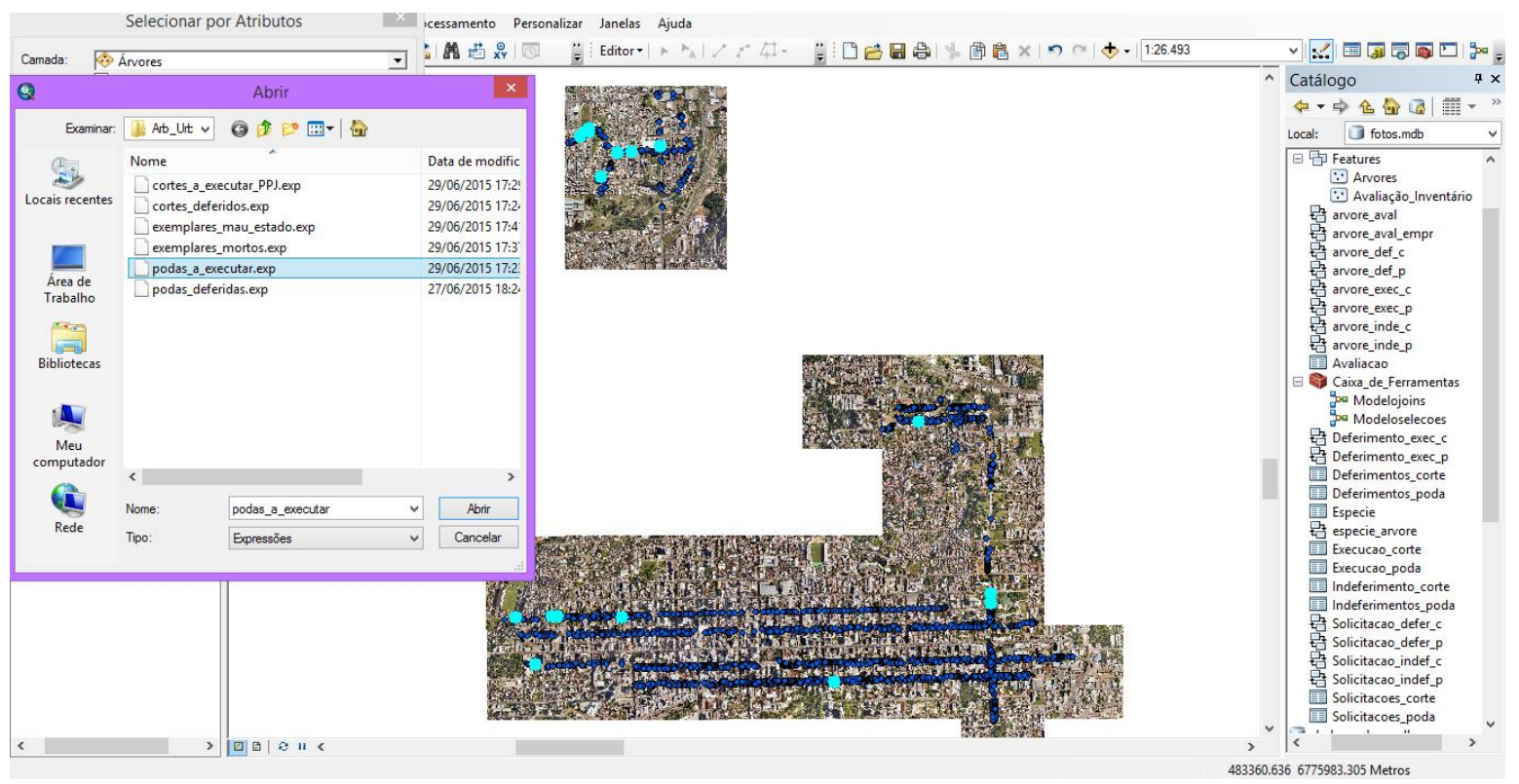

Figura 4. Seleção por atributos, através da fórmula criada, para indicar no mapa os exemplares arbóreos a serem podados

Figure 4. Selection by attributes, using the created formula, to indicate the arboreal specimens to be pruned

Além disso, foram criados relatórios correspondentes às duas consultas citadas, com campos pré-estabelecidos, acionados pela simples seleção do relatório. A Figura 5 mostra um exemplo da execução do relatório de cortes deferidos e ainda não executados, em que os 
pontos em destaque no mapa correspondem à seleção por atributos para os mesmos exemplares.

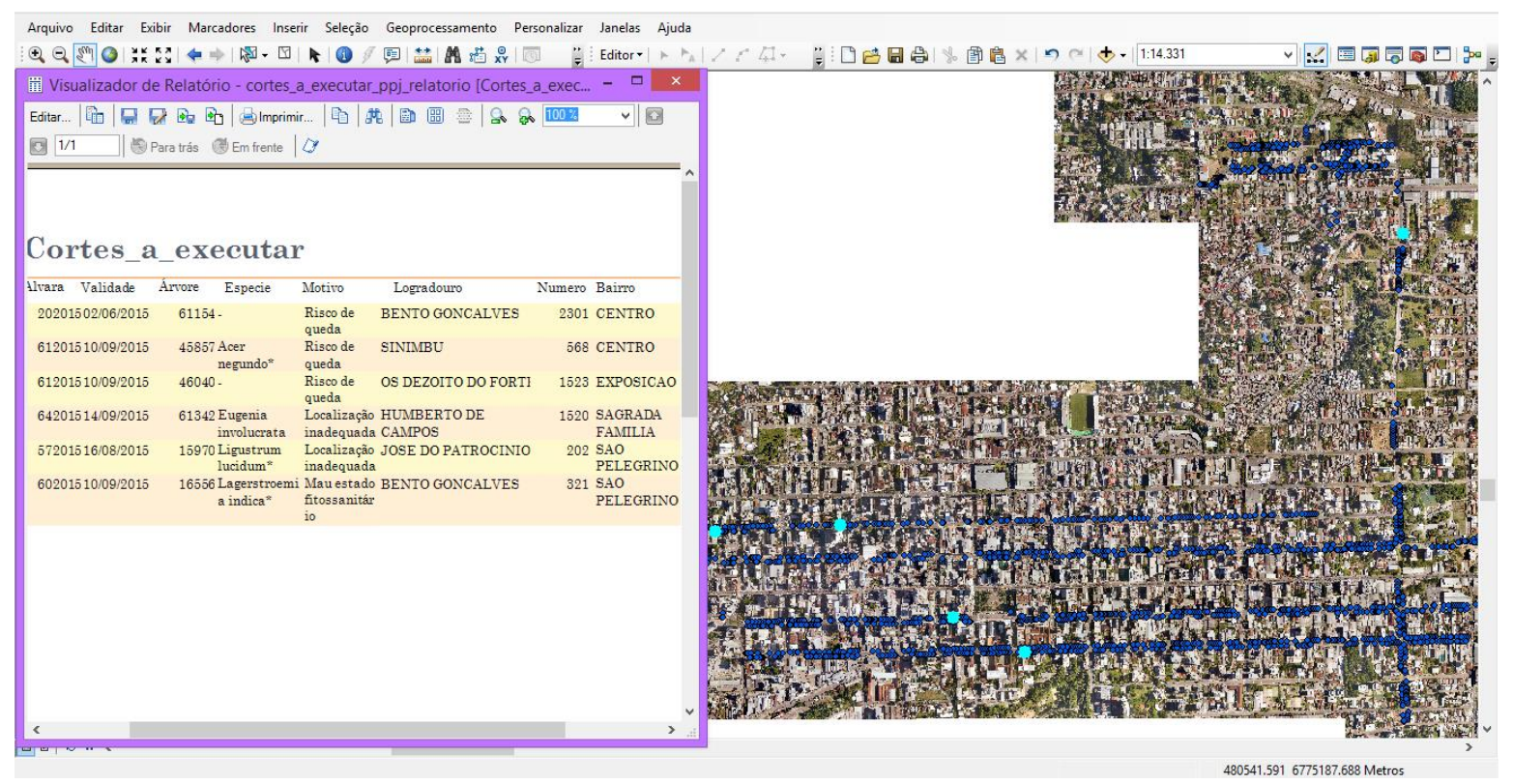

Figura 5. Relatório criado para listar os exemplares arbóreos a serem suprimidos. Os mesmos também foram selecionados e estão destacados no mapa

Figure 5. Created report to list the arboreal specimens to be suppressed. The trees were also selected and highlighted on the map

Atualmente, a organização dos serviços de podas e cortes a executar é realizada manualmente, mas são mantidas planilhas eletrônicas para consulta das informações. A inclusão dos dados no BDG demanda um tempo semelhante ao que é feito atualmente com planilhas eletrônicas, visto que as mesmas podem estar inseridas no BDG, com os devidos relacionamentos entre os campos. Assim, o uso do BDG não aumentaria o tempo gasto com cadastro, enquanto o uso das consultas implementadas no referido BDG poderia diminuir o tempo gasto na organização dos serviços de manejo a serem executados, além de diminuir o tempo de deslocamento das equipes e otimizar o atendimento das demandas da SEMMA.

Além da organização do serviço a executar, é importante o controle do número de podas e cortes executados pelo Setor, o que remete à transparência do serviço público; pois esses dados podem auxiliar a justificar a necessidade de pessoal e equipamento, bem como a demora no atendimento de solicitações feitas pelos cidadãos. Com a implementação do BDG, após a conclusão de cada corte ou poda deferidos, a informação da data de execução é incluída nas tabelas "execução de cortes" e "execução de podas". Assim, ao considerar que as mesmas estão atreladas ao PI "árvores" e às tabelas de deferimentos, são gerados relatórios de podas e de cortes executados em um determinado período, com informações sobre a árvore, sua localização, e data e tipo de serviço executado. Com isso, acredita-se que, apesar 
de demandar mais tempo para a inclusão dos dados, o SisGAU poderá melhorar a qualidade das informações disponíveis, ao diminuir a possibilidade de erros pela inserção integrada de informações.

Foram também inseridas no BDG as informações sobre as espécies das árvores. A consulta dos dados por espécie permite, em longo prazo, uma avaliação mais precisa das aptidões e dos possíveis problemas e incompatibilidades de cada espécie com a arborização de vias públicas. Com isso, o SisGAU está apto para auxiliar na tomada de decisão quanto ao planejamento da arborização urbana no município, pois armazenará informações que permitirão escolher as melhores espécies a serem plantadas para cada situação, e minimizará a ocorrência de problemas futuros (como conflitos com outros equipamentos urbanos). Salienta-se que, além das consultas e relatórios citados, a criação do BDG permitiu a realização de uma série de consultas por diferentes atributos.

Além disso, para facilitar o uso do SisGAU na SEMMA, o projeto criado em ambiente de SIG, com as tabelas relacionadas, pode ficar disponível em rede para todos os funcionários, pois foi criada uma ferramenta, pelo ModelBuilder, para a execução de todos os relacionamentos entre as tabelas, a fim de evitar erros no uso dos dados.

Com o crescimento do uso da Internet e com o aumento da cobrança da população pela transparência do serviço público, a disponibilização de dados georreferenciados na web tem sido cada vez mais utilizada pelo poder público, principalmente prefeituras. Esses sistemas normalmente possuem informações básicas de mapas da cidade, além de dados sobre equipamentos urbanos, serviços sociais, além de normativas de planos diretores, entre outras informações. No entanto, são raros os dados de arborização urbana disponibilizados nessas plataformas; exceções são as cidades de Vitória ${ }^{1}$, Campinas ${ }^{2}$ e Recife $^{3}$, com dados georreferenciados disponíveis na Internet de parte das árvores existentes em áreas públicas.

As informações do BDG criado podem ser disponibilizadas na plataforma web da Prefeitura de Caxias do Sul (GeoCaxias) ${ }^{4}$, juntamente com os dados do Inventário da Arborização Urbana, pois sua estruturação informacional é a mesma utilizada no GeoCaxias. Esses dados podem, então, ser atualizados continuamente pelos técnicos da SEMMA; com isso, a transparência dos serviços executados por essa Secretaria é aumentada.

\footnotetext{
1 PREFEITURA DE VITÓRIA. GeoWeb. Disponível em: <http://geoweb.vitoria.es.gov.br/MapaForm.aspx> Acesso em:05/12/2016. 2 PREFEITURA DE CAMPINAS. Cadastramento das árvores plantadas nas áreas públicas. Disponível em: <http://ambiente campinas.wix.com/qrcode\#! projetos-realizados> Acesso em:05/12/2016.

3 PREFEITURA DO RECIFE. Informações Geográficas do Recife. Disponível em: <http://www.recife.pe.gov.br /ESIG/> Acesso em:05/12/2016.

4 PREFEITURA DE CAXIAS DO SUL. Geo Caxias. Disponível em: <http://geopublico.caxias.rs.gov.br:8814/geocaxias/login> Acesso em:05/12/2016.
} 


\section{CONCLUSÕES}

O SisGAU permitiu o armazenamento das informações dos exemplares arbóreos existentes na arborização urbana de Caxias do Sul. Sua capacidade de integrar informações quantitativas e qualitativas das árvores torna-o uma ferramenta extremamente útil para o gerenciamento dos serviços de manejo das árvores em vias públicas, além de poder subsidiar o planejamento da arborização urbana do município. O BDG criado, através da Internet, pelo GeoCaxias, tem a potencialidade de disponibilizar informações sobre a arborização urbana para a comunidade local, o que aumenta a transparência dos serviços executados pela SEMMA e pode resultar em uma maior conscientização ambiental da população.

A aplicação de outras técnicas e instrumentos durante o seu desenvolvimento (Dicionário de Dados e o modelo conceitual do BDG) potencializam a utilização do SisGAU por facilitar a compreensão de sua estrutura, características e formas de uso e aplicação por parte de funcionários e técnicos que não tenham familiaridade com o software de SIG utilizado e/ou não estiveram envolvidos no seu desenvolvimento.

De acordo com os testes realizados, conclui-se que a implantação do SisGAU pelo poder público municipal poderá: (a) auxiliar os processos de conhecimento, cadastro, avaliação e monitoramento da arborização urbana; (b) contribuir para a melhoria dos serviços executados pela SEMMA, pela otimização dos processos de licenciamento ambiental e manejo de árvores em áreas públicas; e (c) fornecer subsídios para promover ações planejadas, a curto, médio e longo prazos, na implantação e manutenção da arborização urbana. Ressalta-se que iniciativas como o SisGAU podem ser desenvolvidas em todos os âmbitos do funcionalismo público onde a informação geográfica é fundamental para a gestão, pois o SisGAU foi desenvolvido para resolver problemas e aprimorar benefícios de serviços públicos a partir do conhecimento de procedimentos e rotinas internos de serviços executados por um órgão público; nesse caso, a SEMMA.

\section{AGRADECIMENTOS}

À Secretaria Municipal do Meio Ambiente (SEMMA) e à Secretaria do Planejamento Municipal (SEPLAM) da Prefeitura Municipal de Caxias do Sul, pela disponibilização dos dados. 


\section{REFERÊNCIAS}

ALBERTIN, R. M.; ANGELIS, R. de; ANGELIS NETO, G. de; LUIZ, B.; ANGELIS, D. de. Diagnóstico quali-quantitativo da arborização viária de Nova Esperança, Paraná, Brasil. Revista Brasileira de Arborização Urbana, Piracicaba, v. 6, n. 3, p. 128-148, 2011.

ALMEIDA, D. N.; RONDON NETO, R. M. Análise da arborização urbana de três cidades da região norte do Estado de Mato Grosso. Acta Amazonica, Manaus, v. 40, n. 4, p. 647-656, 2010.

CÂMARA, G.; CASANOVA, M. A.; HeMERLY, A. S.; MAGALHÃES, G. C.; MEDEIROS, C. M. B. Anatomia de Sistemas de Informação Geográfica. Campinas: Instituto de Computação, UNICAMP, 1996. 197p.

CASANOVA, M. et al. (Eds.). Bancos de Dados Geográficos. Brasil, MundoGeo, 2005. 506 p.

CAXIAS DO SUL. Decreto № 16.882/2014, de 11 de março de 2014. Caxias do Sul: Câmara Municipal, 2014. 10 p.

ESRI®. ARCGIS. Licence type: Desktop. Version 10.3: ESRI® Inc., Copyright @ ESRI. CDROM, 2015.

FALCE, B. de O.; LEÃO, B. D. de A.; SOUZA, D. M. de; BENDA, F. Análise da distribuição espacial de árvores e arbustos quanto ao porte, à taxonomia e à utilização através de sistema de informação geográfica. Revista da Sociedade Brasileira de Arborização Urbana, Piracicaba, v. 7, p. 23 - 34, 2012.

FARIA, J. L. G.; MONTEIRO, E. A.; FISCH, S. T. V. Arborização de vias públicas do município de Jacareí - SP. Revista da Sociedade Brasileira de Arborização Urbana, Piracicaba, v. 2, n. 4, p. 20-33, 2007.

FRANCO, V. S. M. Gerenciamento da arborização na área do campus da UFMG utilizando ferramentas SIG. 2006. 44 f. Trabalho de Conclusão de Curso (Especialização em Geoprocessamento) - Departamento de Cartografia da Universidade Federal de Minas Gerais, Belo Horizonte, 2006.

LIMA NETO, E. M. Aplicação do Sistema de Informações Geográficas para o inventário da arborização de ruas de Curitiba, PR. 2011. 120 f. Dissertação (Mestrado em Engenharia Florestal) - Departamento de Ciências Florestais da Universidade Federal do Paraná, Curitiba, 2011.

LIMA NETO, E. M.; BIONDI, D.; LEAL, L.; SILVA, F. L. R.; PINHEIRO, F. A. P. Análise da composição florística de Boa Vista-RR: subsídio para a gestão da arborização de ruas. Revista da Sociedade Brasileira de Arborização Urbana, Piracicaba, v. 11, p. 58-72, 2016.

MARANHO, A. S.; PAULA, S. R. P. Diversidade em uma área verde urbana: avaliação qualitativa da arborização do campus da Universidade Federal do Acre, Brasil. Revista Agroambiente On-line, Boa Vista, v. 8, n. 3, p. 404-415, 2014.

MAYER, C. L. D.; OLIVEIRA FILHO, P. C.; BOBROWSKI, R. Análise espacial de conflitos da arborização de vias públicas: caso Irati, Paraná. Revista Floresta, Curitiba, v. 45, n. 1, p. 1120, 2015. 
MECENAS, I.; OLIVEIRA, V. Banco de Dados: do modelo conceitual à implementação física. Rio de Janeiro: Alta Books, 2005. 180 p.

MEIRA, G. R. N.; TEXEIRA, G. G. M.; VENTURIN, P. R. F.; GOTTSTEIN, P.; CAXAMBU, M. G. Avaliação quali-quantitativa de espécies arbóreas no perímetro urbano da cidade de Corumbataí do Sul - PR. Revista da Sociedade Brasileira de Arborização Urbana, Piracicaba, v.10, n. 4, p. 36-49, 2015.

NUNES, R. L.; MARMONTEL, C. V. F.; RODRIGUES, J. P.; MELO, A. G. C. Levantamento qualiquantitativo da arborização urbana do Bairro Ferraropólis na cidade de Garça-SP. Revista da Sociedade Brasileira de Arborização Urbana, Piracicaba, v. 8, n. 1, p. 65-74, 2013.

OLDFIELD, E. E.; WARREN, R. J.; FELSON, A. J.; BRADFORD, M. A. Challenges and future directions in urban afforestation. Journal of Applied Ecology, England, v. 50, n. 5, p. 11691177, 2013.

OliveiRA, A. F.; PEREIRA, J. A. A.; PEREIRA, G. A.; COELHO, S. J.; NEVES, C. L. P.; REZENDE, S. W.; GARCIA, F. H. S. Modalidades de poda avaliadas na arborização viária sob rede elétrica no estado de Minas Gerais. Revista da Sociedade Brasileira de Arborização Urbana, Piracicaba, v. 10, n. 2, p. 1-13, 2015.

OLIVEIRA FILHO, P. C.; SILVA, S. V. K. Um sistema de informações para suporte espacial e de decisões à gestão da arborização urbana no município de Guarapuava, Paraná. Revista da Sociedade Brasileira de Arborização Urbana, Piracicaba, v. 5, n. 3, p. 82-96, 2010.

PERIOTTO, F.; PITUCO, M. M.; HELMANN, A. C.; SANTOS, T. O.; BORTOLOTTI, S. L. Análise da arborização urbana no município de Medianeira, Paraná. Revista da Sociedade Brasileira de Arborização Urbana, Piracicaba, v. 11, n. 2, p. 59-74, 2016.

RABER, A. P.; REBELATO, G. S. Arborização viária do município de Colorado, RS - Brasil: Análise quali-quantitativa. Revista da Sociedade Brasileira de Arborização Urbana, Piracicaba, v. 5, n. 1, p. 183-199, 2010.

ROSSETTI, A. I. N.; PELLEGRINO, P. R. M.; TAVARES, A. R. As árvores e suas interfaces no ambiente urbano. Revista da Sociedade Brasileira de Arborização Urbana, Piracicaba, v. 5, n. 1 , p. 1-24, 2010.

SCHALLENBERGER, L. S.; ARAUJO, A. J.; ARAUJO, M. N.; DEINER, L. J.; MACHADO, G. O. Avaliação de árvores urbanas nos principais parques e praças do município de Irati-PR. Revista da Sociedade Brasileira de Arborização Urbana, Piracicaba, v. 5, n. 2, p. 105-123, 2010.

SPADOTTO, L. G. F.; DELMANTO JR., O. Planejamento e gerenciamento da arborização urbana utilizando técnicas de geoprocessamento. Tekhne \& Logos, Botucatu, v. 1, n. 1, p. 120, 2009. 